\title{
Resistance and Strength of Bio-Compatible Epoxy- Cellulose Composites, as A Function of Concentration and Dispersity of Cellulose Filler
}

\author{
Dmitro Starokadomsky ${ }^{1 *}$, Valerii Barbash ${ }^{2}$, Maria Reshetnyk $^{3}$, Alexandra Starokadomska ${ }^{4}, \mathrm{~L}$ \\ Yudmila Kokhtych ${ }^{5}$, Sergey Shulga ${ }^{1}$ and Olha Yashchenko ${ }^{2}$ \\ ${ }^{1}$ Chuiko Institute of Surface Chemistry, National Academy of Sciences (NAS) of Ukraine \\ ${ }^{2}$ National Technical University of Ukraine, Igor Sikorsky Kyiv Polytechnic Institute, Ukraine \\ ${ }^{3}$ National Museum of Natural History of NAS Ukraine \\ ${ }^{4}$ Institute of Fish Industry of NAS of Ukraine \\ ${ }^{5}$ National Technical University of Ukraine, Igor Sikorsky Kyiv Polytechnic Institute and Institute of Physics NAS of Ukraine \\ Corresponding author: D Starokadomsky, Chuiko Institute of Surface Chemistry, National Academy of Sciences (NAS), \\ General Naunov st., 17, Kyiv, 03042, Ukraine
}

\section{ARTICLE INFO}

Received: 慧 October 20, 2020

Published: 幽 October 28, 2020

Citation: D Starokadomsky, V Barbash, M Reshetnyk, A Starokadomska, L Kokhtych, S Shulga, O Yashchenko. Resistance and Strength of Bio-Compatible EpoxyCellulose Composites, as A Function of Concentration and Dispersity of Cellulose Filler. Biomed J Sci \& Tech Res 31(3)-2020. BJSTR. MS.ID.005103.

Keywords: Epoxy; Cellulose; Nanocellulose; Microcellulose; Microscopy; Compression Strength; Bending Strength; Microhardness; Fire-Resistance; Swelling in Acetone; in $\mathrm{H}_{2} \mathrm{O}_{2}$ in Sea-Water

\section{ABSTRACT}

The purpose of the present study was the investigation of structural and mechanical properties of epoxy polymer composites filled with nano-, micro- and mesocellulose. In prapared composites, cellulosics play role of a reinforcement constituent while epoxy resin is the matrix. The effect of composite composition with the application of different amounts of nano- and microcellulose on compression and tensile strenght, microhardness, fire-resistance and swelling was investigated. The method of optical microscopy showed that the microstructure is complemented by a long fibrils to give well-compatible compositions, forming hard and resistant plastics. Bending strengt increases in 1.21.3 times (after filling by nanocellulose) and Modulus at bending increases from 1.6 to 2.5 (at $20 \%$ of nanocellulose). Fire- and Abrasion-resistance increases in 1.2-1.4 times, and adhesion to steel in 2-2.5 times. Filling with nanocellulose and micromeso-disperce particles of lignincellulose (waste-paper utilisated product) let obtain a composites resistant to destruction in acetone solutions and other aggressive media $\left(35-60 \% \mathrm{H}_{2} \mathrm{O}_{2}\right.$, sea-water etc). Due to the numerous advantages, such as low cost of cellulosic raw materials, their high availability and abundance, as well as nontoxicity, it can be regarded as perspective filler of the epoxy composits with high mechsnical properties and chemical resistance which may have a wide practical use.

\section{Introduction}

Composites based on epoxy oligomers filled by fibers and biomaterials, due to their high adhesion, heat resistance, low shrinkage during curing and other properties, are widely used as sealing compounds for repair materials, adhesives, compounds and glues [1-5]. There is a growing trend to use cellulose biomaterials as fillers and/or reinforcers in epoxy polymer composites. Today, scientists are conducting research on the use of various kinds of additives in polyepoxy bio-composites in order to commercial cheaping and increase their characteristics, including strength, resistance, chemical and thermal stability [6-23]. Biomaterials have a flexibility during processing, highly specific stiffness, and low cost (on a volumetric basis), that make them attractive to manufacturers. Due to environment and sustainability issues, this century has witnessed remarkable achievements in green technology in the field of materials science through the development of biocomposites. The development of high-performance materials made from renewable natural resources is increasing worldwide. Such resources include plant materials, the main component of which is cellulose [6-24].

A biocomposite's properties are influenced by a number of variables, including the fiber type, environmental conditions 
(where the plant fibers are sourced), processing methods, and any modification of the fiber. It is also known that recently there has been a surge of interest in the industrial applications of composites containing biofibers reinforced with biopolymers [8-26].

Cellulose is a widespread natural biopolymer of polysaccharide nature and with fibrous structure and unique properties due to which the scope of its use is increasing every year [27-29]. More often, cellulose-based materials are used as fillers for various types of composite materials of organic and inorganic nature [7-23]. Epoxy-Cellulose Composites (ECC) are biocompatible, tree-imitating and resistant. Therefore, ECC are well for the bio-, restauration and medical applications in the field-terms (field hospitals, departure laboratories, expeditions). According to Nair et al. [15] the adding of $20 \pm 2 \mathrm{wt} . \%$ of nanocellulose-fiber increases mechanical parameters (modulus, strength, and deformation) and resistance of the resulting composites. Nanocellulose fibers based on bleached softwood pulp were used to prepare cellulose nanocomposites using conventional vacuum infusion [16]. The obtained composites had a porous structure with a random orientation of the fibers. They obtained an increase in strength (from 89 to $107 \mathrm{MPa}$ ) and a modulus of elasticity in bending (from 2.8 to $4.2 \mathrm{MPa}$ ) - with 13 vol.\% of nanocellulose [16]. Moreover, the mechanical indicators "show anisotropy" - in particular, the flexural and storage moduli can vary by $25 \%$ depending on the direction of the loads.

On the other hand, an interesting possibility is the application of cellulose-inorganic waste from the paper industry as a filler for composite materials. The paper industry is an important source of environment pollution because of the consumption of a large amount of water and formation of a huge quantities of wastewaters, which differ in composition, depending on the range of products produced. During treatment of such wastewaters, a large amount of solid wastes which contains, not only natural fibers but also mineral components, is formed. The main part of this wastes remains unused and requires the development of effective disposal methods. Methods for solid wastes of paper industry utilization have been described in many publications (as a component of concrete mixtures, in the manufacture of bricks, as a base of gypsum plaster, as a component of wood-fiber boards, as a filler of insulation blocks) [24-25] but none of the investigated methods has acquired industrial use. For nowadays, only landfill or incineration is used on an industrial scale for the utilization of solid wastes of paper industry, which has a negative impact on the environment. Therefore, the problem of efficient utilization of such wastes is an urgent one. One of the possible effective methods of its utilization can be the application in epoxy composites [7-25,3032]. From a literature search it follows that these materials, (with their apparent simplicity and solid age of use) have been studied sporadically. Most researchers get positive effects without any theoretical explanations (which are replaced by low-informative microscopy). Meanwhile, not only interesting effects are possible here, but also mechanisms of physicochemical interaction. The aim of this paper is to evaluate and to compare the effect of cellulose structure and type on properties of the epoxy composits.

\section{Materials and Methods \\ Materials}

Epoxy polymer composites were prepared, in which cellulose has various dispersion and form of particles. We used microcrystalline cellulose with particle size of 50-300 $\mu \mathrm{m}$ (Russia). Nanocellulose was obtained in Igor Sikorsky Kyiv Polytechnic Institute (Ukraina) in laboratory conditions from organosolvent cellulose from stalks of Miscanthus $\mathrm{x}$ giganteus as a result of acid hydrolysis with ultrasonic treatment of suspension [29,30]. Meso-disperce cellulosic product were obtained from waste-paper at Malin paper mill (Ukraine) and the fraction less than $1 \mathrm{~mm}$ were used in this research; the content of organic and inorganic substances is $29,7 \%$ and $71,3 \%$, respectively.

\section{ECC Preparation}

Compositions of the ECC were prepared by mixing weights of cellulose derivatives from $5 \mathrm{wt} \%$ to $20 \mathrm{wt} \%$ with Epoxy520 epoxy resin (Czech production), followed by the addition of PEPA hardener (resin: hardener ratio 5:1) and constant mechanical stirring under normal conditions. After 3 days of initial curing, samples of the obtained composites were subjected to heat treatment at a temperature of $65^{\circ} \mathrm{C}$ for $5-7$ hours for mechanical and thermal tests or at $30{ }^{\circ} \mathrm{C}$ for at least 5-7 days for tests on swelling and resistance in aggressive liquids.

\section{ECC Structure and Properties Investigation}

The surface structure of the cellulosic materials and ECC was studied using an optical microscope and a Scanning Electron Microscope (SEM) JSM-35 JEOL (Japan). Mechanical tests of the obtained ECC samples were carried out in accordance with standard techniques. Compression strength of ECC samples was determined on a Louis Shopper press-machine with the application of cylindrical samples (diameter of the sample was $6.5 \mathrm{~mm}$, height - $11 \pm 0.5 \mathrm{~mm}$ ) in accordance with ISO 604: 2002. To evaluate the tensile strength, plates $6 \times 1 \times 0.2 \mathrm{~cm}$ were prepared. The parameter was measured on base $\mathrm{L}=3 \mathrm{~cm}$ in bending test mashine ITM (USSR). Brinell microhardness was determined on a hard-meter PTM (USSR), with $3 \mathrm{~mm}$ steel hemisphere. Tests on the resistance in liquids or so-called swelling were carried out according to ISO $62: 2008$ - by measuring the weight of tablets $(1 \times 1 \times 0.1 \mathrm{~cm}$ in size $)$ after removal from the liquid, wiping and short-term drying (5$10 \mathrm{~min}$ ) at norm conditions. Solutions of acetone, 35\% H2O2 and $20 \%$ nitric acid were used for this purpose. The peel adhesion test was carried out according to (ISO 4624:2002). The fire-resistance test was carried by contact of template with an open fire source (laboratory portable gas mini-burner) as described in [20]. 


\section{Results and Discussion}

\section{Study of the structure of ECC}

Optical microscopy shows (Figure 1) that meso-disperce cellulose (waste-paper) is distributed in epoxy in large interlacing agglomerates up to 200-300 microns in size. Micro-sized cellulose is distributed in form of microfibers up to 500 microns in length. Nanocellulose has a glassy morphology, with a particle's particle size of less than 500 microns. Thus, these fillers (taken in sufficient quantities, for example 5-20 wt\%) should have different effects on the mechanical and resistance properties of the epoxy composite.
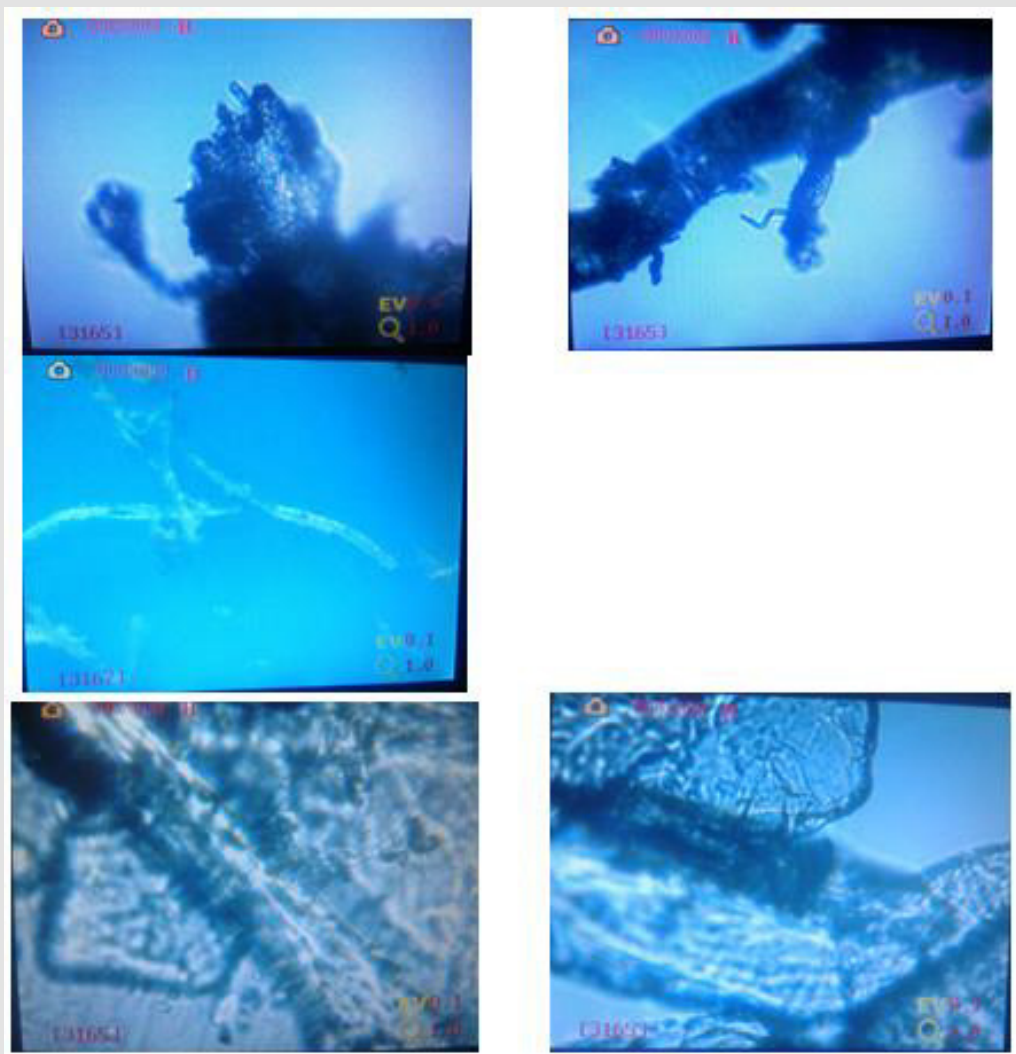

Figure 1: Optical micrograph of cellulose fillers $(\times 400)$

a) Mesocellulose

b) Microcellulose

c) Nanocellulose

\section{Investigation of Mechanical and Physical Strength of ECC}

In order to evaluate the efficiency of cellulosic derivatives, the comparison between the ECC and the unfilled epoxy polymer was made in terms of compression and tensile strength, fire-resistance and microhardness. Investigation of the mechanical properties of obtained composite testifies about good compatibility between epoxy and cellulosic materials (due to the fact that both materials contain a significant content of hydroxyl groups) and about high strength and flexibility of the composites. The principle for hydrogen bonds between cellulose and epoxy is shown in Figure 2. The results of the investigation of mechanical and physical strength of ECC is shown in Table 1. From Table1 it can be seen that the strength and modulus in bending after filling increases in the case of nanocellulose and mezocellulose. This means that the loose cellulose structures embedded in the polymer network in some cases form a more bending and elastic frame than fragments of an epoxy polymer. At the same time, filling enhances abrasion resistance (since the weight of the abraded mass decreases) and adhesion to steel. The compressive strength after filling does not change (Table 1).

The fire resistance as a result of filling naturally increases, which is obviously caused by the higher fire resistance of the filler - cellulose. The composites do not acquire the damping properties: as the unfilled polymer, as filled self-ignite after the start of combustion, even without source of fire. Thus, the filling of cellulose derivatives allows to obtain epoxy masses that are well formed and give polymer-composites with enhanced properties. The results of investigation of microhardness of initial unfilled epoxy and ECC is shown in Table 2. As can be seen from Table 2, microhardness of ECC after filling is preserved or slightly reduced. Moreover, the increase in cellulosic additives content leads to the increase in the brittleness of composites. 


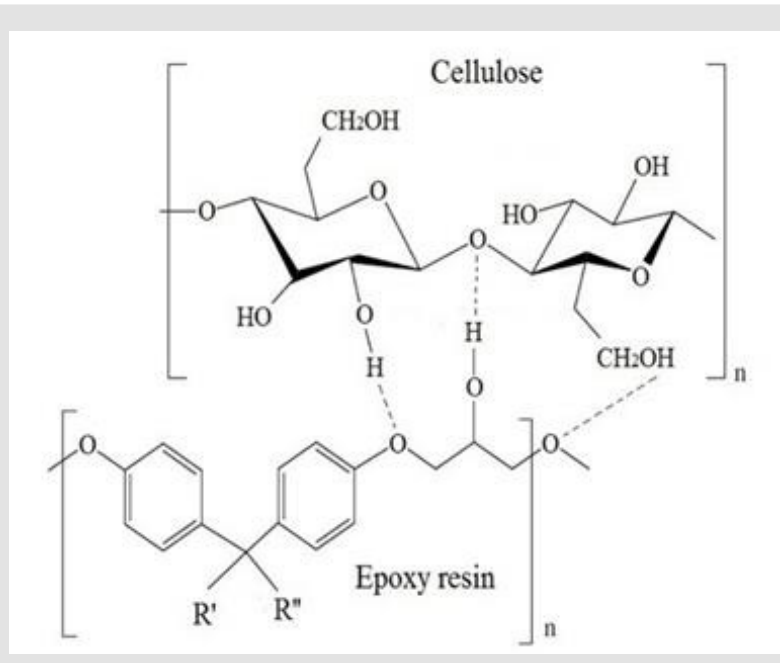

Figure 2: Scheme for formation of intermolecular hydrogen bond and possible chemical bond between cellulose and epoxy resin (from our open-accessed works [20,21]).

Table 1: Strength parameters of composites (*-estimated data).

\begin{tabular}{|c|c|c|c|c|c|c|c|c|}
\hline & & \multicolumn{3}{|c|}{ Filled with microcellulose } & \multicolumn{3}{|c|}{ Filled with nanocellulose } & \multirow{2}{*}{$\begin{array}{c}\text { Filled with } \\
20 \text { wt \% of } \\
\text { Mesocellulose } \\
\text { (waste-paper) }\end{array}$} \\
\hline & Unfilled & 5 wt \% & 10 wt. $\%$ & 20 wt \% & 5 wt \% & 10 wt. $\%$ & 20 wt $\%$ & \\
\hline Bending strenght, $\mathrm{MPa}$ & 49.0 & 45.1 & - & 44.1 & 65.7 & - & 60.8 & 50.0 \\
\hline BendingModulus, I*1000,MPa & 1.58 & 1.22 & - & 1.21 & 1.47 & - & 2.45 & 1.96 \\
\hline Compression strength, MPa & 96.4 & $102.4^{*}$ & 102.5 & - & $96.4^{*}$ & 93.4 & - & 90.4 \\
\hline CompressionModulus, MPa & 1.3 & - & 1.3 & - & - & 1,4 & - & 1,2 \\
\hline Abrasion resistance, $1000 / \mathrm{mg}$ & 10 & 11 & 11.5 & 12.5 & 11 & 11 & 11 & 11 \\
\hline Fire resistance, s & 1 & 1 & - & 1.3 & 1.3 & - & 1.4 & 2 \\
\hline
\end{tabular}

Table 2: Microhardness (N) of epoxy composites at different depths of immersion.

\begin{tabular}{|c|c|c|c|}
\hline \multirow{2}{*}{ Sample } & \multicolumn{3}{|c|}{ Immersion, $\boldsymbol{\mu m}$} \\
\cline { 2 - 4 } & $\mathbf{2 0}$ & $\mathbf{3 0}$ & $\mathbf{5 0}$ \\
\hline Unfilled & 300 & 400 & 500 \\
\hline Filled with 5 wt \% of microcellulose & 300 & 400 & 500 \\
\hline Filled with 20 wt \% of microcellulose & 250 & 350 & $450^{*}$ \\
\hline Filled with 20 wt \% of mesocellulose & 300 & 350 & $500^{*}$ \\
\hline
\end{tabular}

\section{Investigation of Swelling Properties of ECC}

Epoxy plastics are quite resistant to many aggressive mediums. But there are a number of solvents and mediums, such as acetone, nitric acid, peroxides, etc. which are very aggressive for polyoxides. The results of the investigation of chemical resistance of ECC in acetone:ethylacetate (1:1), concentrated 55\% $\mathrm{H}_{2} \mathrm{O}_{2}$ and $1 \%$ $\mathrm{NaOH}$ are given in Figure 3. In concentrated hydrogen peroxide (a known oxidizing disinfectant in biomedicine), the durability of ECC composites can be higher, compared to a polymer without filling. This is confirmed by a decrease in the degree of swelling for $5 \%$ and $20 \%$ of filling (but not for $10 \%$, Figure 4 ). The effect of different types of cellulose on the swelling is approximately the same. With prolonged time, $20 \%$ of mezocellulose is most effective for restraining the swelling of the composite. An important factor is the concentration of $\mathrm{H}_{2} \mathrm{O}_{2}$. for example, in a $35 \%$ solution, samples can remain intact for a whole year - only their appearance changes (Figure $5 \mathrm{~A}$ ). But in a $50-60 \% \mathrm{H}_{2} \mathrm{O}_{2}$ solution, they quickly (in 1-5 days, Figure $5 \mathrm{~B}$ ) swell with a large gain in mass and volume (Figure 4) - and then degrade. When exposed to seawater (a common corrosive environment for composite products), an initial washout (loss of weight) in 1 day can be seen for all samples (except for the composite with microcellulose, Figure 6). 


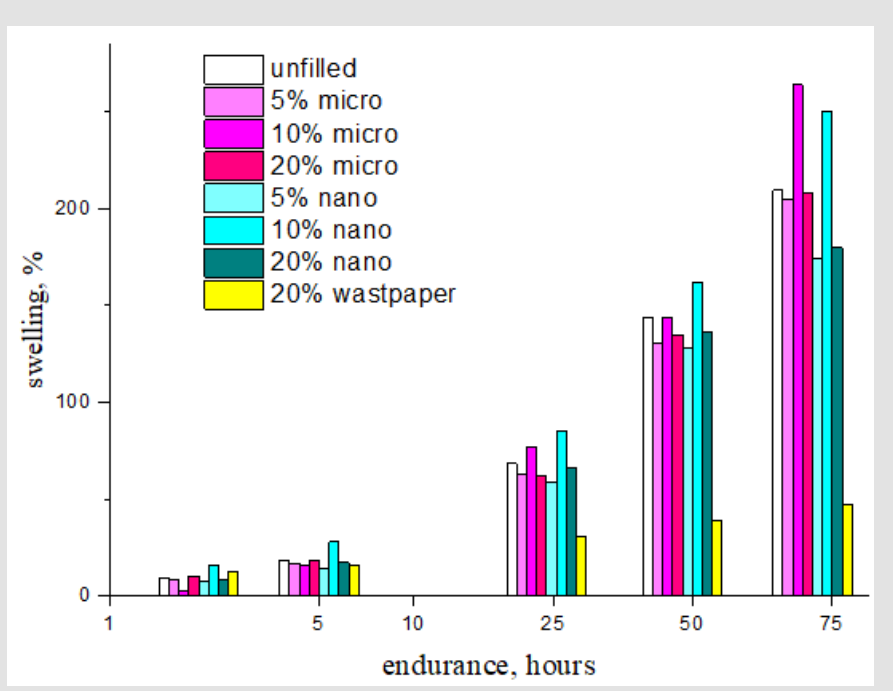

Figure 3: Effect of time on efficiency of ECC swelling in $55 \% \mathrm{H}_{2} \mathrm{O}_{2}$.

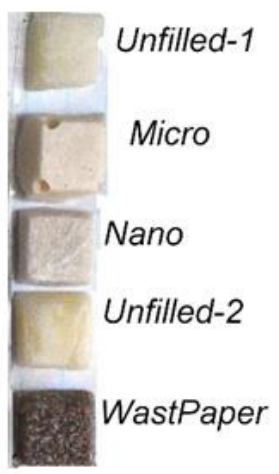

A
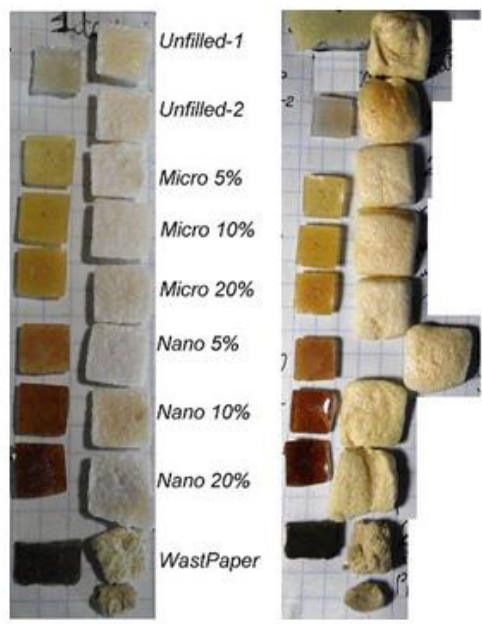

Figure 4: Visual changes of templates after endurance in $\mathrm{H}_{2} \mathrm{O}_{2}$ :

a) $10 \%$-filled in $35 \% \mathrm{H}_{2} \mathrm{O}_{2}$, after 1 year

b) $5-20 \%$ filled in $55-60 \% \mathrm{H}_{2} \mathrm{O}_{2}$, after 1 day (left) and 5 days (righ).

Table 3: Swelling of templates in acetone:ethylacetate mix (1:1). (Unfilled templated 1 and 2 differ by his initial mass).

\begin{tabular}{|c|c|c|c|c|c|c|c|c|c|}
\hline Time, days & Unfill.-1 & Unfill.-2 & Micro 5\% & Micro 10\% & Micro 20\% & Nano 5\% & Nano*10\% & Nano $20 \%$ & Wastp20\% \\
\hline 0 & 0,0 & 0,0 & 0,0 & 0,0 & 0,0 & 0,0 & 0,0 & 0,0 & 0,0 \\
\hline 0,08 & 8,0 & 12,1 & 6,7 & 6,0 & 8,5 & 10,7 & 14,0 & 12,5 & 6,3 \\
\hline 0,25 & 11,4 & 18,1 & 8,3 & 6,0 & 12,8 & 12,1 & destruct & 14,8 & 6,3 \\
\hline 1 & 25,0 & 20,9 & destruct & destruct & destruct & 14,1 & & 14,8 & 7,8 \\
\hline 2 & destruct & destruct & & & & 0,7 & & 18,8 & 13,0 \\
\hline 3 & & & & & & destruct & & 23,2 & 17,7 \\
\hline 6 & & & & & & & & 25,0 & 25,0 \\
\hline 8 & & & & & & & & 33,5 & 25,0 \\
\hline 9 & & & & & & & & 33.5 & 27,6 \\
\hline 10 & & & & & & & & destruct & 27,6 \\
\hline 15 & & & & & & & & & 28,1 \\
\hline
\end{tabular}

Note: * - estimated data 
Table 4: Swelling of $10 \%$-filled templates in acetone.

\begin{tabular}{|c|c|c|c|c|c|}
\hline Time, days & Unfilled-1 & Unfilled-2 & Micro & Nano & Wastepaper \\
\hline 0 & 0,0 & 0,0 & 0,0 & 0,0 & 0,0 \\
\hline 0,17 & 15,1 & - & 9,4 & 12,8 & 8,3 \\
\hline 1 & 19,0 & 20,1 & 13,3 & 14,9 & 11,1 \\
\hline 2 & 27,0 & 23,4 & 16,0 & 12,8 & 13,3 \\
\hline 3 & destruct & destruct & 18,8 & 17,0 & 23,9 \\
\hline 9 & & & 21,5 & 17,0 & 23,9 \\
\hline 14 & & & destruct & 17,0 & 23,9 \\
\hline 21 & & & & 13,5 & 11,7 \\
\hline
\end{tabular}

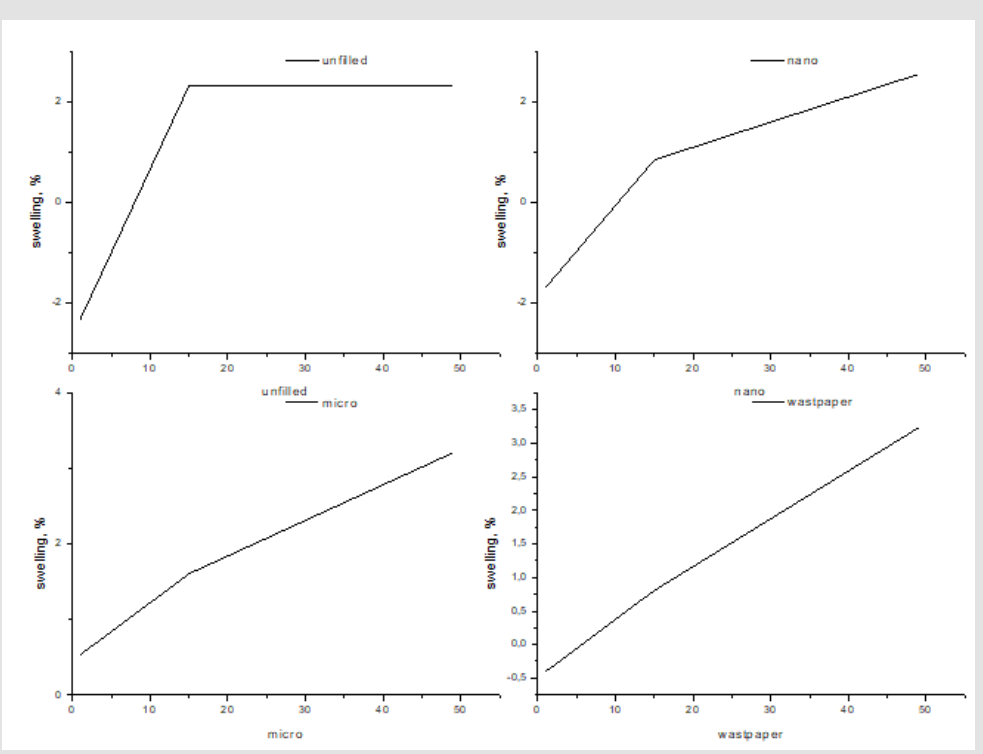

Figure 5: Effect of time on efficiency of ECC swelling in sea water.

\section{Figure 6:}

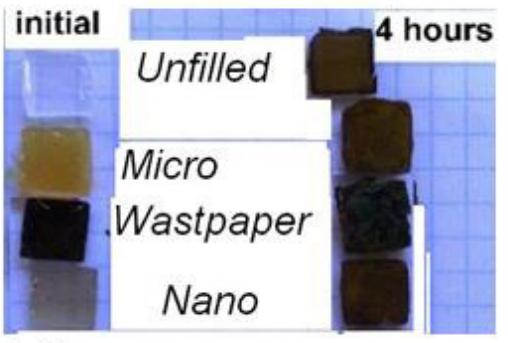

A, 4 hours

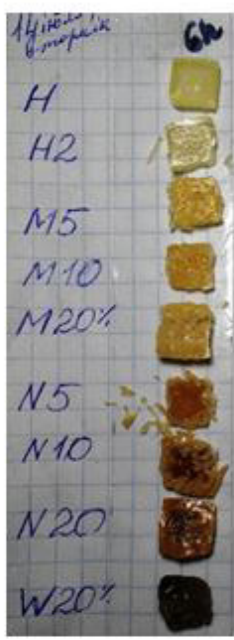

B, 6 hours

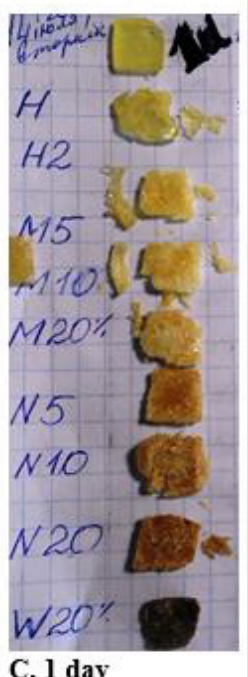

C, 1 day

A) Photo of 10\%-filled ECC composites before and after impregnation in acetone: 1 - unfilled; 2, 3 - filled with microcellulose and with microcellulose and clattro-chelate red pigment; 4 - filled with wastepaper (mesocellulose); 5 - filled with nanocellulose.

B,C) Photo of filled ECC composites before and after impregnation in acetone-ethylacetate mix: $\mathrm{H}$, $\mathrm{H} 2$ - unfilled; $\mathrm{M}$ - filled with (5-20\%) microcellulose; 5 - filled with (5-20\%) nanocellulose; 4 - filled with $20 \%$ wastepaper (Mesocellulose). 
Subsequently, the swelling of the unfilled one stops after half a month and does not exceed $2.5 \%$ in a month and a half (which corresponds to the standard data for polyepoxides). After filling, the composite swells less actively in the first half-month of aging. But then the swelling of filled templates continues (albeit at a lower rate) throughout the entire holding time (Figure 6). The effect of cellulose as a filler is clearly seen when the composites are exposed to acetone-containing solvents (Table $3 \& 4$ ). Table 3 shows well the instability of unfilled polyepoxide in acetone solvents. This severely limits the use of epoxy plastics. The introduction of microcellulose leads to an even more noticeable decrease in resistance (destruction during the day, Table 3), while the degree of swelling decreases. The introduction of 5 and 20\% nano-cellulose imparts the highest stability to the composites - up to 10 days without destruction (Nano20\%, Table 3). Interesting data on 20\% with Waste-paper the composite does not degrade and swells slightly. The swelling rate then increases, but after 6 days the swelling for 20\% Wastepaper stabilises. In pure acetone, the swelling dynamics of unfilled ones is similar to acetone:ethylacetate. Unfilled polymer templates swell quickly and disintegrate on the 3-rd day of exposure (Table 4). Microcellulose slightly improves the resistance to swelling but does not save it from destruction and (Table 4). Nanocellulose and wastepaper provide even higher resistance to swelling and nondegradability.

The photo of epoxy composites for the evaluation of visual changes before and after impregnation in acetone and acetoneethylacetate mix is given in Fig. 7. We see significant destructive changes almost immediately. Decomposition or lay-separation of the samples begins within a few hours, especially in the acetoneethylacetate mix. Their appearance well displays the digital data in Tables $3 \& 4$.

\section{Conclusion}

As a result of the study, it was found that the introduction of cellulose fillers allows to obtain viscous masses, which after curing turn into wood-like composites. The morphology of the compositions reflects the fibrous nature of cellulose, which therefore integrates well into the supramolecular structure of epoxy. The effect of fillingtype on the strength is ambiguous and depends on the dispersion and concentration of the filler. A number of the main properties were studied and thay have not changed much after filling (compressive strength, tensile, microhardness). For other characteristics (abrasion resistance adhesion, elastic modulus), a unambiguous gain was observed. After filling with cellulosic materials, the resistance of the epoxide to aggressive liquids such as $35-60 \%$ hydrogen peroxide, aceton (or acetone:ethylactate) and sea water, increases. As a rule, Epoxy composites with 5 and 20 wt $\%$ of cellulose, do not decompose in acetone in first days (unlike unfilled ones) and swell weaker in hydrogen peroxide or acetone:ethylacetate. Also, after filling, the fire resistance of composites increases by 1.3-2 times. As a result, it can be concluded that it is promising and prospactive to obtain ECC composites for the manufacture of bio-eco-compatible wood-based products and of the multi-purpose.

\section{Funding}

This research received no external funding.

\section{Conflicts of Interest}

The authors declare no conflict of interest.

\section{Acknowldgement}

To Researcher V.Galysh, Ph.D, S.Shulga, Ph.D., for providing micro-cellulose samples, to Scientist A. Nikolaychuk for providing a digital optical microscope.

\section{References}

1. O Polovina, B Gorelov, A Gorb, A Nadtochiy, D Starokadomsky, et al. (2019) Epoxy filled with bare and oxidized multi-layered graphene nanoplatelets: a comparative study of filler loading impact on thermal properties. Journal of Materials Science 54(28).

2. Mostovoy A, Yakovlev A, Tseluikin V, Lopukhova M (2020) Epoxy Nanocomposites Reinforced with Functionalized Carbon Nanotubes. Polymers 12: 1816.

3. Starokadomsky D, Reshetnyk M (2019) Microfilled epoxy-composites, capable of thermo-hardening and thermo-plasticization after hard heating $\left(200-300^{\circ} \mathrm{C}\right)$ - for "in-field $\backslash$ offroad" use in bio-,agro-, medservice. Biomed J Sci \& Tech Res 19: 14118-14123.

4. Rassokhin D, Starokadomsky D, Ishenko A, Tkachenko O, Reshetnyk M (2020) Determining the strength and thermal, chemical resistance of the epoxy polymercomposite filled with basalt micronano fiber in the amount of 15-80\% by weight. Eastern European J. of Advanced Technologies 2(10): 55-63.

5. AD Starokadomsky, M Reshetnyk, A Ishenko (2017) Filling with the Graphene Nanoplates as a Way to Improve Properties of EpoxyComposites for Industrial and Geophysical Machinery. American Journal of Physics and Applications 5(6): 120-125.

6. Starokadomsky D, Barbash V, Shulga S, Reshetnyk M (2020) Effect of disperse \& surface of nano- \& micro-cellulose on properties of epoxypolymer composite. Composites \& Nanostructures-2020. 12(1-45): 5362.

7. Matykiewicz D (2020) Biochar as an Effective Filler of Carbon Fiber Reinforced Bio-Epoxy Composites Processes 8(724): 1-13.

8. Matykiewicz D (2020) Hybrid Epoxy Composites with Both Powder and Fiber Filler: A Review of Mechanical and Thermomechanical Properties. Materials 13(8): 1802.

9. Rojas J, Bedoya M, Ciro Y (2015) Current trends in the production of cellulose nanoparticles and nanocomposites for biomedical applications. In Poletto M (eds.), Cellulose. IntechOpen, pp. 193-228.

10. Tanase Opedal M, Espinosa E, Rodríguez A, Chinga Carrasco, G Lignin (2019) A Biopolymer from Forestry Biomass for Biocomposites and 3D Printing. Materials 12(18): 3006.

11. Faruka O, Bledzkia AK, Fink HP, Sain M (2012) Biocomposites reinforced with natural fibers: 2000-2010. Progress in Polymer Science 37(11): 1552-1596.

12. Pickering KL, Aruan Efendy MG, Le TM (2016) A review of recent developments in natural fibre composites and their mechanical performance. Composites: Part A 83: 98-112. 
13. V Barbash, 0 Yaschenko (2019) Developping the technology of obtaining microcrystalline cellulose from flax fibers. Advanced Mater Technol for Environmental Appl 3(2): 247-254.

14. Szabo L, Imanashi S, Tetsuo F, Hirose D, Ueda (2019) Lignin as a functional green coating on carbon fiber surface to improve interfacial adhesion in carbon fiber reinforced polymers Materials (Basel) 12: 2-15.

15. V Pankeev, A Nikiforov, E Sveshnikova, L Panova (2013) New Fillers for Epoxy Compounds Based on Modified Cellulose-Containing Waste. International Polymer Science and Technology 40(9): 57-60.

16. Nair SS, Dartiailh C, Levin DB, Yan N (2019) Highly toughened and transparent biobased epoxy composites reinforced with cellulose nanofibrils. Polymers (Basel) 11: 612.

17. Nissila T, Hietala M, Oksman K (2019) A method for preparing epoxycellulose nanofiber composites with an oriented structure. Composites Part A: Applied Science and Manufacturing 125: 105515.

18. S Hossain, M Rahman, A Jamwa, P Gupta, S Thakur (2019) Processing and characterization of pine epoxy based composites. AIP Conference Proceedings 2148: 030017.

19. Karnani R, Krishnan M, Narayan R (1997) Biofiber-reinforced polypropylene composites. Polymer Engineering \& Science 37(2): 476483.

20. Musaeva AY (2020) Development of functional purpose epoxy composites. Plasticheskie massy (1-2): 33-34.

21. Sigareva NV, Barbash VA, Yashchenko OV, Shulga SV, Starokadomsky DL (2020) Influence of cellulose particles on chemical resistance, mechanical and thermal properties of epoxy composites. Biophysical Bulletin 43: 57-70.

22. Shulga SV, Starokadomsky DL, Levina AM, Zorina AV, Ogenko VM (2015) The effect of microcrystalline cellulose on the physicomechanical property of epoxy composites. Khimiya, fizyka ta tekhnolohiya poverkhni Surface chemistry, physics and technology T 6(3): 380-387.

23. N Nagarajan, A Balaji, S Kathar, N Ramanujam (2020) Effect of agro waste $\alpha$-cellulosic micro filler on mechanical and thermal behavior of

\section{ISSN: 2574-1241}

DOI: $10.26717 /$ BJSTR.2020.31.005103

Dmitro Starokadomsky. Biomed J Sci \& Tech Res

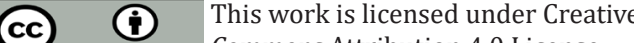
Commons Attribution 4.0 License

Submission Link: https://biomedres.us/submit-manuscript.php epoxy composites. International Journal of Biological Macromolecules 152: 327-339.

24. Sarikaya E, Callioğlu H, Demirel H (2019) Production of epoxy composites reinforced by different natural fibers and their mechanical properties. Composites Part B. 167: 461-466.

25. Zhan Q, Khan MU, Lin X, Yi W, Lei H (2020) Green-composites produced from waste residue in pulp and paper industry: A sustainable way to manage industrial wastes. Journal of Cleaner Production 262: 121251.

26. Mehmood S, Khaliq A, Ranjha SA (2010) The use of post-consumer wood waste for the production of wood plastic composites: A Review. Proceedings Venice 2010, Third International Symposium on Energy from Biomass and Waste, Venice, Italy 8-11.

27. Alavi M (2019) Modifications of microcrystalline cellulose (MCC), nanofibrillated cellulose (NFC), and nanocrystalline cellulose (NCC) for antimicrobial and wound healing applications. e-Polymers 19: 103-119.

28. Bifulco A, Silvestri B, Passaro J, Boccarusso L, Roviello V (2020) A New Strategy to Produce Hemp Fibers through a Waterglass-Based Ecofriendly Process. Materials 13: 1844.

29. Barbash VA, Yashchenko OV, Opolsky VO (2018) Effect of Hydrolysis Conditions of Organosolv Pulp from Kenaf Fibers on the Physicochemical Properties of the Obtained Nanocellulose. Theor Exp Chem 54: 193-198.

30. Barbash VA, Yashchenko OV, Vasylieva OA (2019) Preparation and Properties of Nanocellulose from Miscanthus x giganteus. Journal of Nanomaterials pp. 3241968.

31. Starokadomsky DL, Barbash V, Reshetnyk M, Diamant V, Moshkovska N (2020) The surface properties of epoxy nanocomposites modified with nanoparticles of nanocellulose. The International research and practice conference "Nanotechnology and nanomaterials" (NANO-2020). Abstract Book of participants of the International research and practice conference, 26-29 August 2020, Lviv. In Olena Fesenko(Eds.), Kyiv: LLC Computer-publishing, information center pp. 552.

32. O Daramola, J Olajide, S Agwuncha, M Mochane, E Sadiku (2019) Nanostructured Green Biopolymer Composites for Orthopedic Application Springer Edit Chapter 7: 159-192.

$\begin{array}{ll}\text { BIOMEDICAL } & \text { Assets of Publishing with us } \\ \text { RESEARCHES } & \text { - Global archiving of articles } \\ & \text { - Immediate, unrestricted online access } \\ & \text { - Rigorous Peer Review Process } \\ & \end{array}$

